\title{
Stability of Vertical Double-Diffusive Interfaces In The Presence Of Material Diffusion
}

\author{
Khaled S. M. Al Mashrafi \\ Department of Basic Sciences, College of Applied and Health Sciences \\ A'Sharqiyah University \\ P.O. Box 42, P.C. 400, Ibra, Sultanate of Oman \\ khaled.almashrafi@asu.edu.om
}

\section{Extended Abstract}

Suppose a fluid of two components of different densities is placed on a cool surface maintained at a uniform temperature, the component with the higher solidification temperature solidifies first and settles at the bottom of the container if it is the heavier one [1]. After that, because of the solidification process a layer appears at the bottom of the container near the cold surface. This layer is known as a mush and contains both the light fluid component and the heavy solid crystals [2]. As solidification continues, the mushy layer becomes thicker, and the experiments indicate that there is a strong interaction between the mushy layer and the fluid above this layer [3]. As a result, the interface between the two becomes unstable and plumes rising from the mushy layer appear [4-8].

The solidification process depends on temperature, pressure, gravity, and concentration, in addition to the different coefficients of diffusion of viscosity, thermal diffusivity, and material diffusivity. There are many studies dealing with the mushy layers. Early studies dealt with solidification of fluid alloys. This type of solidification occurs in a wide range of environmental, geophysical, and industrial applications, including sea ice [9-11], salt fingers [12-17], mantle plumes [1820], Earth's inner-core boundary [21-24], crystal growth [25-26], and iron casting [1, 27-28].

The experiments of researchers were motivated by the need to understand the imperfections known as freckles in iron castings. By using a solution of water and ammonium chloride (NH4CL) near eutectic composition, the experimental work by Copely et. al [27] was the first experiment that studies the freckle chains. They placed the melt on a cool surface. The melt started to solidify in the vertical direction (directional solidification), and this leads to a region of mixed phase (solid and liquid) which is the mushy layer and it is unstable. Then this process leads to appearance of thin plumes from the mushy layer and rose to the liquid layer and they concluded that these plumes are related to freckles [27, 29-30].

The dynamics of compositional plumes has been investigated experimentally and theoretically. The experimental work showed that the compositional plumes are stable [3,31-34], while the theoretical work showed that it is unstable for all non-zero values of Grashoff Reynold number [4,35]. This was found to be true even if more than one plume is present and in the presence/absence of vertical boundaries, rotation and magnetic fields [36-41]. These theoretical studied on the stability of compositional plumes were held in the absence of material diffusion. We think that the presence of material diffusion might play an important role in the stability analysis because diffusion is normally a stabilizing factor. Also the profile of the basic concentration of light material was taken to be very simple and there is no doubt a more realistic form may lead to different results. So in this paper, we extend the previous work on the stability of compositional plumes to include the material diffusion. The analysis carried out on the dynamics of compositional plumes assumed the Boussinesq approximation and used the equations of conservation of mass, momentum, heat, concentration of light material and state. In this case the equations take the form

$$
\begin{gathered}
\nabla \cdot u=0, \\
\rho_{0}\left[\frac{\partial u}{\partial t}+(u \cdot \nabla) u\right]=-\nabla p+\rho_{0} v \nabla^{2} u-\rho \mathrm{g} \hat{z}, \\
\frac{\partial T}{\partial t}+u \cdot \nabla T=\kappa \nabla^{2} T
\end{gathered}
$$




$$
\begin{gathered}
\frac{\partial C}{\partial t}+u \cdot \nabla C=\kappa_{m} \nabla^{2} C, \\
\rho=\rho_{0}\left[1-\alpha\left(T-T_{0}\right)-\beta\left(C-C_{0}\right)\right],
\end{gathered}
$$

where $\boldsymbol{u}$ is velocity vector, $p$ is pressure, $T$ is temperature, $C$ is concentration, $t$ is time, $v$ is kinematic viscosity, $\square \square \square$ is density $\square \square g$ is local acceleration of gravity, $\hat{z}$ is unit vector along z-axis, $\kappa$ is thermal diffusivity, $\kappa_{m}$ is material diffusivity, $\alpha$ is coefficient of thermal expansion, $\beta$ is coefficient of compositional expansion, and Subscript 0 denotes a constant reference value.

It is found that the presence of material diffusion reduces the growth rate but the plume remains unstable for all values of the parameters.

\section{References}

[1] R. N. Hills, D. E. Loper and P. H. Roberts, "A thermodynamically consistent model of a mushy zone", Q. J. Mech. Appl. Maths., 36, 505 - 539, 1983.

[2] D.E. Loper and P.H. Roberts, "On the motion of an iron-alloy core containing a slurry", I. Geophys Astrophys Fluid Dyn., 9 , 289 - 321, 1978.

[3] M. G. Worster, "Instabilities of the liquid and mushy regions during solidification of alloys", J. Fluid Mech., 237, 649 $-669,1992$.

[4] I. A. Eltayeb and D. E. Loper, "On the stability of vertical double-diffusive interfaces, Part1. A single plane interface", J. Fluid Mech., 228, 149 - 181, 1991.

[5] I. A. Eltayeb and D. E. Loper, "On the stability of vertical double-diffusive interfaces, Part2. Two parallel interfaces", J. Fluid Mech., 267, $251-271,1994$.

[6] I. A. Eltayeb and D. E. Loper, "On the stability of vertical double-diffusive interfaces, Part3. Cylindrical interfaces", J. Fluid Mech., 353, 45 - 66, 1997.

[7] P. Garaud, "Double-diffusive convection at low Prandtl number," Annu. Rev. Fluid Mech. 50, 275-298,2018.

[8] M. A. Daniel and G. Peter, "Convective phenomena in mushy layers", Annual Review of Fluid Mechanics, 52, 93-119, 2020.

[9] K. O. Bennington, "Some crystal growth features of sea ice”, J. of Glaciology, 4(63), 669-688, 1963.

[10] R. A. Lake and E. L. Lewis, "Salt rejection by sea ice during growth", J. Geophys. Res. 75(3), 583 - 597, 1970.

[11] J. S. Wettlaufer, M. G. Worster and H. E. Huppert, "Natural convection during solidification of an alloy from above with application to the evolution of sea ice", J. Fluid. Mech., 344, $291-316,1997$.

[12] M. E. Stern, "The salt fountain and thermohaline convection", Tellus, 12, $172-175,1960$.

[13] J. Y. Holyer, "The stability of long, steady, two-dimensional salt fingers", J. Fluid Mech., 147,169 - 185, 1984.

[14] X. Zhang, L. Wang, H. Zhu, and C. Zeng, "Modeling of salt finger convection through a fluid-saturated porous interface: Representative elementary volume scale simulation and effect of initial buoyancy ratio", physics of fluids, 32:8, 2021.

[15] F. Rehman and O. P. Singh, "Salt finger convection at marginal stability," Geophys. Astrophys. Fluid Dyn. 111(5), $323-332,2017$.

[16] L. N. Howard and G. V. Veronis, "Stability of salt fingers with negligible diffusivity", J. Fluid Mech., 239,511 522, 1992.

[17] R. W. Schmitt, "Observational and laboratory insights into salt-finger convection”, Prog. Oceanogr., 56, 419 - 433, 2003.

[18] W. J. Morgan, "Convection plumes in the lower mantle", Nature,230,42 -43, 1971.

[19] I. Kumagai, "On the anatomy of mantle plumes: effect of the viscosity ratio on entrainment and stirring", Earth Planet. Sci. Lett., 198, 211 - 224, 2002.

[20] J. Monteux, D. Andrault, M. Guitreau, H. Samuel, and S. Demouchy, “ A mushy Earth's mantle for more than 500 Myr after the magma ocean solidification”, Geophys. J. Int., 221, 1165-1181, 2020.

[21] J. Verhoogen, "Heat balance of the Earth's core”, Geophys. J. R. Astron. Soc., 4, 276 - 281, 1961. 
[22] D.E. Loper and P.H. Roberts, "On the motion of an iron-alloy core containing a slurry", I. Geophys . Astrophys. Fluid Dyn., 9,289 - 321, 1978.

[23] H. Shimizu, J. P. Poirier and J. L. Le Mouel, "On crystallization at the inner core boundary", Phys. Earth Planet. Int., $151,37-51,2005$.

[24] L. Huguet, T. Alboussiere, M. I. Bergman, R. Deguen, S. Labrosse, and G. Lesceur, "Structure of a mushy layer under hypergravity with implications for earth's inner core”, Geophys. J. Intl, 204, 1729-1755, 2016.

[25] A. K. Sample and A. Hellawell, "The mechanisms of formation and prevention of channel segregation during alloy solidification", Metall. Trans., A 15A, 2163-2173, 1984.

[26] J. R. Sarazin, and A. Hellawell, "Channel formation in $\mathrm{Pb}-\mathrm{Sn}, \mathrm{Pb}-\mathrm{Sb}$ and $\mathrm{Pb}-\mathrm{Sn}-\mathrm{Sb}$ alloy ingots and comparison with the system NH4Cl-H2O”, Met. Trans., 19, 1861-1871, 1988.

[27] S. M. Copley, A. F. Giamei, S. M. Johnson and M. F. Hornbecker, "The origin of freckles in unidirectionally solidified castings", Metall. Trans., 1, 2193 - 2204, 1970.

[28] Y. Zhao, B. Zhang, H. Hou, W. Chen and M. Wang, "Phase-field simulation for the evolution of solid/liquid

interface front in directional solidification process", J. Mater. Sci. Technol., 35, 1044-1052, 2019.

[29] G. Y. Ding, , A. J. Wells and J. Q. Zhong, "Solidification of binary aqueous solutions under periodic cooling. Part 1. Dynamics of mushy-layer growth", J. Fluid Mech., 870, 121-146, 2019.

[30] G. Y. Ding, , A. J. Wells and J. Q. Zhong, "Solidification of binary aqueous solutions under periodic cooling. Part 2. Distribution of solid fraction", J. Fluid Mech. 870, 147-174, 2019.

[31] H. E. Huppert, "The fluid mechanics of solidification", J. Fluid Mech., 212, 209 - 240, 1990.

[32] C. F. Chen and F. Chen, "Experimental study of directional solidification of aqueous ammonium chloride solution", $J$. Fluid Mech. 227, 567-586, 1991.

[33] S. Classen, M. Heimpel, and U. Christensen, "Blob instability in rotating compositional convection", Geophys. Res. Lett., 26:1, 135 - 138, 1999.

[34] M. Nishimura, M. Wakamatsu and A. M. Morega, "Oscillatory double-diffusive convection in a rectangular enclosure with combined horizontal temperature and concentration gradients", Int. J. Heat Mass Transfer, 41(11) ,1601 - 1611, 1998.

[35] I. A. Eltayeb, and E. A. Hamza, "Compositional convection in the presence of rotation”, J. Fluid Mech., 354, 277299, 1998.

[36] I. A. Eltayeb, E. A. Hamza, J. A. Jervase, E. A. Krishnan and D. E. Loper, "Compositional convection in the presence of a magnetic field. I. A single interface", Proc. R. Soc. Lond. A, 460, 3505 - 3528, 2004.

[37] I. A. Eltayeb, E. A. Hamza, J. A. Jervase, E. A. Krishnan and D. E. Loper, "Compositional convection in the presence of a magnetic field. II. A Cartesian plume", Proc. R. Soc. Lond A, 461, 2605 - 2633, 2005.

[38] M. A. Al-Lawatia, T. B. Elbashir, I. A. Eltayeb, M. M. Rahman, and E. A. Balakrishnan, "The dynamics of two interacting compositional plumes in the presence of a magnetic field", Geophys. Astrophys. Fluid Dyn., 105(6), 586 $615,2011$.

[39] T. B. Elbashir, M. A. Al-Lawatia, and I. A. Eltayeb, "The dynamics of two interacting compositional plumes", Geophys. Astrophys. Fluid Dyn.104, 29 - 63, 2010.

[40] K. S. Al-Mashrafi and I. A. Eltayeb, "The Influence of Boundaries on the Stability of Compositional Plumes", Open Journal of Fluid Dynamics, 4; 83-102, 2014(a).

[41] K. S. Al-Mashrafi and I. A. Eltayeb, "The stability of a rotating Cartesian plume in the presence of vertical boundaries “,Open Journal of Fluid Dynamics, 4; 207-225, 2014(b). 